\title{
Gel filtration studies on immunoreactive gastrin in serum from Zollinger-Ellison patients
}

\author{
JENS F. REHFELD AND FLEMMING STADIL \\ From the Department of Clinical Chemistry, Bispebjerg Hospital, and the Department of Surgical Gastro- \\ enterology C, Rigshospitalet, Copenhagen, Denmark
}

SUMMARY Sera from 15 patients with the Zollinger-Ellison syndrome were subjected to gel filtration on Sephadex G-50 superfine columns $(10 \times 2000 \mathrm{~mm})$. The concentration of gastrin in the effluent was determined by a sensitive radioimmunoassay.

Immunoreactive gastrin was eluted in four components in 14 sera. (1) Component I, eluted in the same position as proinsulin, constituted $9 \cdot 7 \pm 1 \cdot 2$ (mean \pm SEM) $\%$ of the total immunoreactivity. (2) Component II ('big gastrin') eluted between proinsulin and insulin constituted $57 \cdot 8 \pm 4 \cdot 1 \%$ (mean $\pm \mathrm{SEM}$ ) of immunoreactive gastrin. In three sera with the highest concentration of gastrin, component II appeared biphasic. (3) Component III ('little gastrin') was distributed in two peaks; the first one eluted in the same position as the heptadecapeptide gastrin II made up $17 \cdot 4 \pm 2 \cdot 7$ (mean $\pm \mathrm{SEM}) \%$ of the total immunoreactivity; the second one eluted in the same position as gastrin I constituted $9 \cdot 5 \pm 1 \cdot 3$ (mean \pm SEM) \%. (4) Component IV ('minigastrin') was eluted immediately before the salt peak and constituted $5.6 \pm 1.4$ (mean \pm SEM) $\%$. In one serum only components I and II were present. After incubation with trypsin all immunoreactivity in components I and II was converted to heptadecapeptide-like gastrins.

The findings suggest that immunoreactive gastrin in serum from Zollinger-Ellison patients is circulating in at least four components of different molecular size.

Yalow and Berson have shown (1970, 1971, and 1972) that plasma from patients with the ZollingerEllison syndrome contains up to three components of immunoreactive gastrin. The major fraction of immunoreactive gastrin was a component with an estimated molecular weight of 7000 , named 'basic' or 'big' gastrin. A small component showed chromatographic and electrophoretic characteristics corresponding to those of the heptadecapeptide gastrin of Gregory and Tracy (1964) and was named 'little' gastrin. Finally, serum from three patients contained a component eluted in the void volume of Sephadex G-50 columns. This large component was called 'big-big' gastrin, and it comprised 0.9 to $2.0 \%$ of the total immunoreactivity.

In addition to the three components described by Yalow and Berson, another large immunoreactive gastrin component, named component $\mathrm{I}$, has been found in sera from normal subjects and patients with pernicious anaemia (Rehfeld, 1972). On gel filtration this component was eluted in the same

Received for publication 22 February 1973. position as proinsulin, after the void volume, and it was detected in 19 of 22 sera: $18.4 \pm 7.6 \%$ (mean \pm SD) of the total immunoreactivity was present in this component. The characteristics of component I thus obviously differs from those of the 'big-big' gastrin.

The purpose of the present study was to describe the components of immunoreactive gastrin in sera from 15 Zollinger-Ellison patients as defined by gel chromatography on columns of high resolution.

\section{Materials}

Sera were obtained from 15 patients with the Zollinger-Ellison syndrome. The concentration of immunoreactive gastrin in the sera ranged from 140 to $131000 \mathrm{pmol}$ per $\mathrm{l}$. The other materials were obtained from the following sources: Sephadex G-50 superfine from Pharmacia Inc, Uppsala, Sweden; synthetic human gastrin I from Imperial Chemical Industries, Cheshire, England; highly purified porcine gastrin II (lot no. 66/138) from Division of Biological Standards, National Institute of Medical 
Research, England; human albumin from Behringwerke, Marburg am Lahn, Germany; $\mathrm{Na}^{125} \mathrm{I}$ (specific radioactivity $\sim 10 \mathrm{mCi}$ per $\mu \mathrm{g}$ ) from Hoechst, Frankfurt am Main, Germany; ${ }^{22} \mathrm{NaCl}$ (specific activity $100 \mathrm{mCi}$ per $\mathrm{mg}$ ) from the Radiochemical Centre, Amersham, England; trypsin, 'essentially free of chymotrypsin' (lot no. 1012 15) from Calbiochem, San Diego, Calif, USA; human monocomponent insulin and porcine proinsulin were kindly provided by $\mathrm{Dr}$ J. Schlichtkrull and Lise Heding, PhD, NOVO, Copenhagen.

The radioactivity was measured in a well-type scintillation counter (Selektronik, model 54, Copenhagen).

\section{Methods}

FRACTIONATION PROCEDURES

Serum samples or dilutions of serum in a volume of 1.0 or $1.5 \mathrm{ml}$ were applied to Sephadex G-50 superfine columns $(10 \times 2000 \mathrm{~mm})$ with a constant flow rate of $5.4 \mathrm{ml}$ per hour at $20^{\circ} \mathrm{C}$. The columns were eluted with $0 \cdot 1 \mathrm{M}$ sodium phosphate, $\mathrm{pH} 7 \cdot 4$, containing $0.6 \mathrm{mM}$ ethyl mercuric thiosalicylate.

The columns were calibrated with ${ }^{125} \mathrm{I}$-albumin, ${ }^{22} \mathrm{Na}$, monocomponent human insulin, porcine proinsulin, synthetic human gastrin I, and highly purified porcine gastrin II. Furthermore ${ }^{125} \mathrm{I}$-albumin, insulin, proinsulin, and ${ }^{22} \mathrm{Na}$ were added to each serum sample before application to the column for the internal standardization.

Serum samples of $1.0 \mathrm{ml}$ were incubated for 30 minutes with $1.0 \mathrm{ml}$ of a solution of trypsin $(1 \mathrm{mg}$ per $\mathrm{ml} 0.25 \mathrm{M}$ sodium phosphate, $\mathrm{pH} 7$ ). After incubation the mixture was applied to the Sephadex G-50 superfine columns.

\section{RADIOIMMUNOANALYSIS}

Gastrin was measured with a radioimmunoassay as previously described (Rehfeld, Stadil, and Rubin, 1972). The accuracy of the assay in determination of gastrin in Zollinger-Ellison sera is illustrated by the dilution experiments shown in figure 1 .

Immunoreactive insulin was measured by a wickchromatographic assay (Ørskov, 1967).

\section{Results}

In 14 sera the gastrin immunoreactivity was distributed in four components of which component III was resolved in two peaks (fig 2). Component I was eluted in the same position as proinsulin, and component II between proinsulin and insulin. In three sera component II was biphasic. The first peak in component III was eluted in the same fractions as the heptadecapeptide gastrin II and the second one

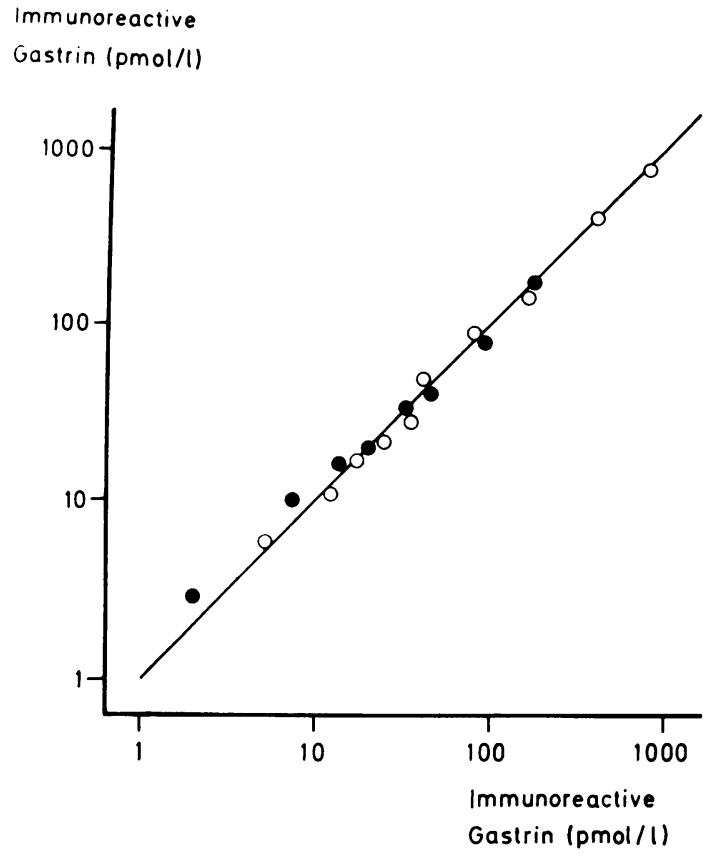

Fig 1 Dilution of sera from two Zollinger-Ellison patients, one witl a very high concentration of gastrin in serum $(\mathrm{O}-\mathrm{O})$, the other one with a slightly elevated concentration of gastrin in serum (-O). The concentrations measured (abscissa) are plotted against expected concentrations (ordinate).

as the heptadecapeptide gastrin I. A small peak was eluted immediately before the salt peak (component IV).

The distribution of the gastrin immunoreactivity in the individual peaks varied individually (see table):

\begin{tabular}{|c|c|c|c|c|c|}
\hline \multirow{2}{*}{$\begin{array}{l}\text { Patient } \\
\text { No. }\end{array}$} & \multirow{2}{*}{$\begin{array}{l}\text { Component } \\
\text { I }\end{array}$} & \multirow{2}{*}{$\begin{array}{l}\text { Component } \\
\text { II }\end{array}$} & \multicolumn{2}{|c|}{ t Component III } & \multirow{2}{*}{$\begin{array}{l}\text { Component } \\
\text { IV }\end{array}$} \\
\hline & & & Peak I & Peak 2 & \\
\hline HA & 0.11 & 0.42 & $0 \cdot 17$ & $0 \cdot 17$ & 0.13 \\
\hline PM & 0.17 & 0.60 & 0.14 & 0.07 & 0.02 \\
\hline PB & 0.06 & 0.60 & $0 \cdot 22$ & 0.08 & 0.04 \\
\hline $\mathbf{A R}$ & 0.11 & 0.52 & 0.08 & $0 \cdot 17$ & 0.12 \\
\hline $\mathbf{R R}$ & 0.12 & 0.40 & 0.36 & 0.08 & 0.04 \\
\hline DR & 0.05 & 0.42 & $0 \cdot 19$ & 0.14 & 0.20 \\
\hline JN & 0.10 & 0.72 & 0.07 & 0.06 & 0.03 \\
\hline $\mathbf{K K}$ & 0.17 & 0.58 & $0 \cdot 14$ & 0.06 & 0.05 \\
\hline KO & 0.08 & 0.53 & 0.30 & 0.06 & 0.03 \\
\hline LB & 0.04 & 0.47 & $0 \cdot 26$ & 0.19 & 0.04 \\
\hline IK & 0.05 & 0.77 & 0.07 & 0.08 & 0.03 \\
\hline ES & 0.05 & 0.74 & 0.10 & $0 \cdot 10$ & 0.01 \\
\hline TS & 0.06 & 0.94 & 0.00 & 0.00 & 0.00 \\
\hline MK & 0.10 & 0.55 & 0.16 & 0.10 & 0.09 \\
\hline ER & $0 \cdot 18$ & 0.39 & $0 \cdot 35$ & 0.07 & 0.01 \\
\hline Mean & 0.097 & 0.578 & $0 \cdot 174$ & 0.095 & 0.056 \\
\hline SD & 0.047 & 0.159 & 0.107 & 0.051 & 0.055 \\
\hline
\end{tabular}

Table Fractions of immunoreactivity in gastrin components in sera from 15 patients with the ZollingerEllison syndrome 
pmol/l

Immunoreactive

counts/min

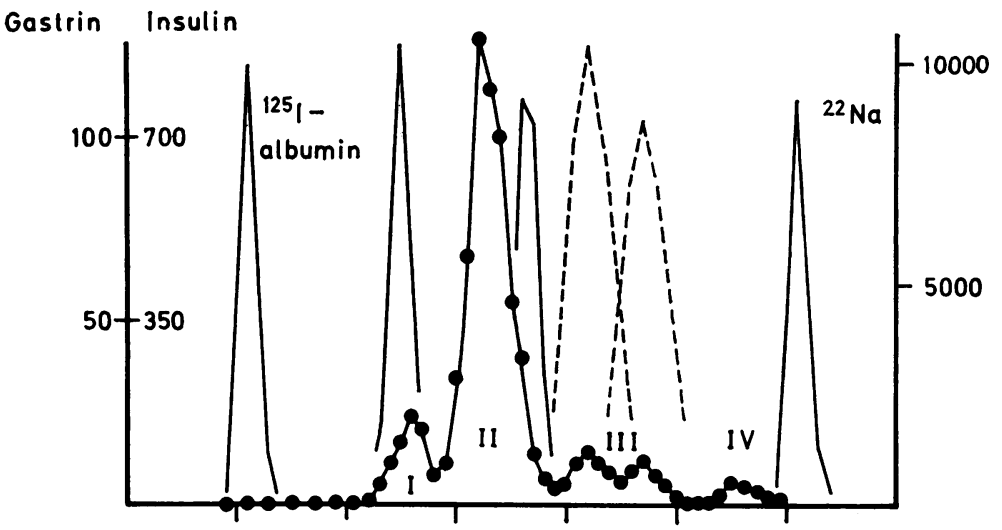

Fig 2 Elution diagrams of sera from two Zollinger-Ellison patients. Immunoreactive serum gastrin (O-O) was distributed into four components as indicated by Roman numerals. The elution of immunoreactive insulin as proinsulin and monocomponent insulin (-) and heptadecapeptides, gastrins I and II (- - - -) is indicated. The heptadecapeptide gastrin II was eluted before gastrin I.

At the top an example of a serum with a monophasic component II. The elution pattern of gastrin in this serum is typical

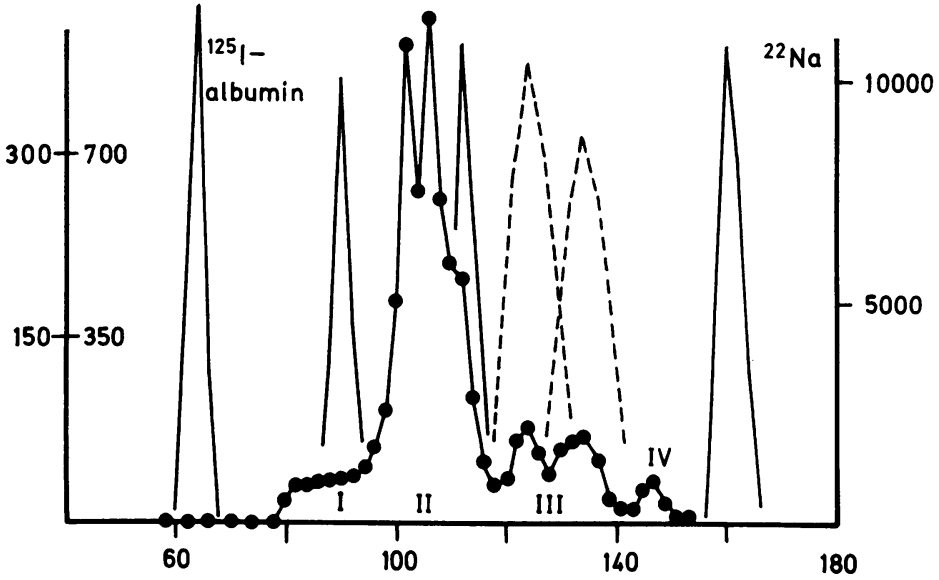
for most of the sera studied. At the bottom an example of a serum with a biphasic component II. Three of 15 sera showed this pattern.

Effluent volume (ml)

$9 \cdot 7 \pm 4 \cdot 7$ (mean \pm SD) $\%$ was found in component I. In most sera component II constituted most of the immunoreactivity, $57.8 \pm 15.9 \%$ (mean of all sera \pm SD). Peaks 1 and 2 in component III contained 17.4 and $9.5 \%$ of the immunoreactivity respectively; and $5.6 \%$ was found in component IV. In one serum only components I and II were present. Examples of different elution patterns are shown in figures 2 and 3.

After incubation with trypsin all immunoreactivity from components I and II in all sera was found in the two first peaks in component III as illustrated in figure 4.

\section{Discussion}

The present study has shown that immunoreactive gastrin in serum from Zollinger-Ellison patients emerges by Sephadex gel filtration in four components. The three components have been described previously in serum from normal subjects and from patients with pernicious anaemia (Rehfeld, 1972). In the Zollinger-Ellison patients a smaller fraction of the total immunoreactivity was found in component I and a larger one in component II.

Component II appeared biphasic in three of 15 Zollinger-Ellison sera. The concentration of gastrin in these sera ranged among the highest observed. The biphasic pattern suggests that component II contains at least two gastrins. Recent studies in our laboratories using ion-exchange chromatography have confirmed that two gastrins of different charge are present in component II in serum from these Zollinger-Ellison patients.

By gel filtration on Sephadex G-50 fine columns of moderate size $(10 \times 1100 \mathrm{~mm})$, component III 
pmol/l

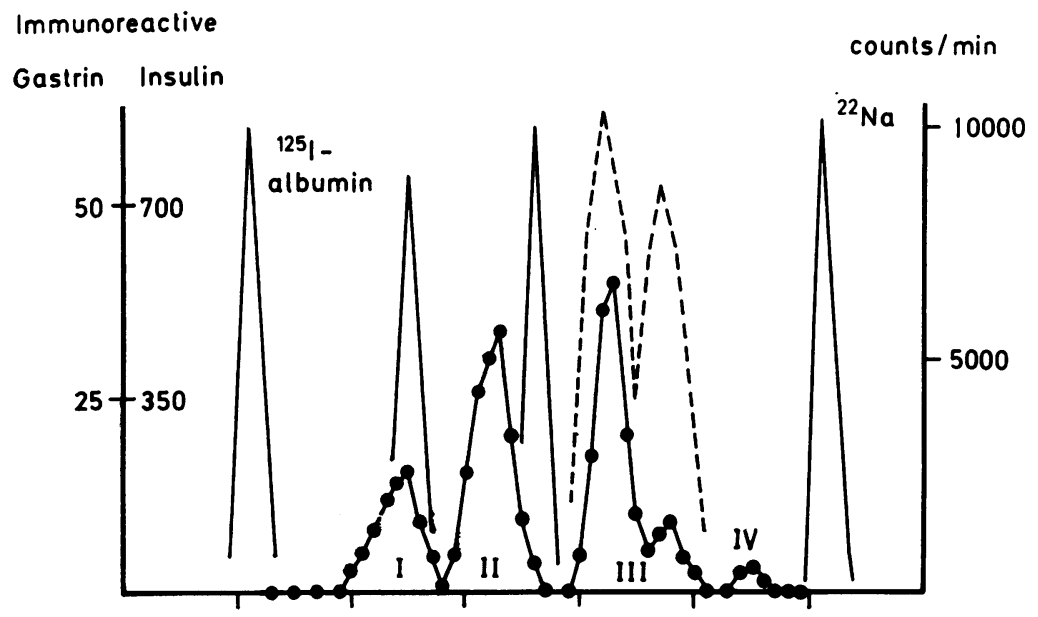

Fig 3 Elution diagrams of sera from two ZollingerEllison patients. The elution of immunoreactive serum gastrin (O-O), insulin (-), and the heptadecapeptide gastrins $I$ and II (-..--) is indicated as in figure 2. At the top a serum in which a great part of the immunoreactive gastrin was present in the first peak of component III. At the bottom a serum in which all gastrin

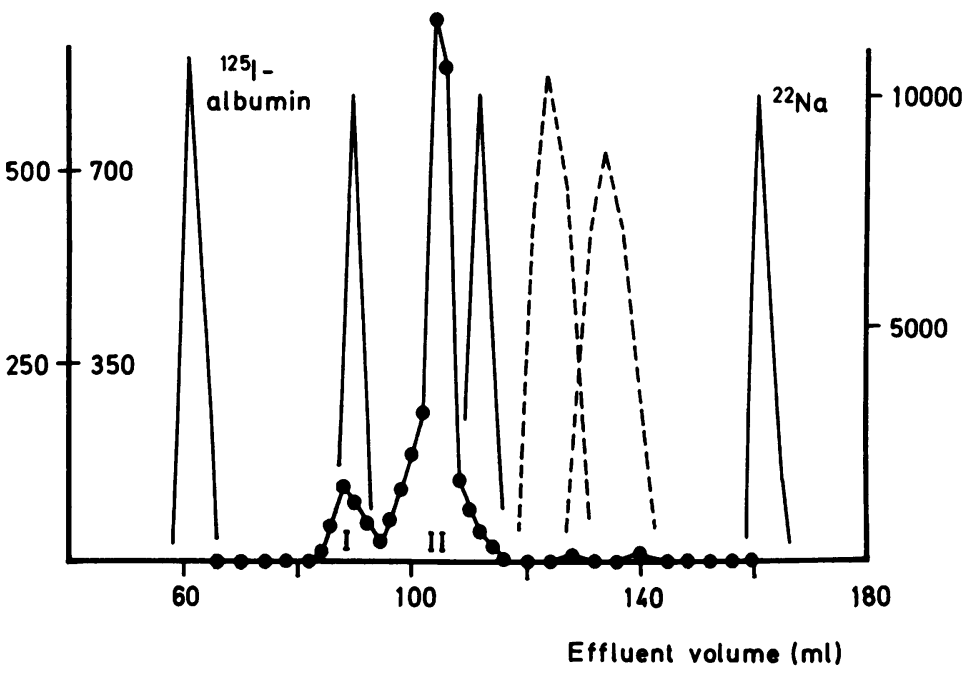
immunoreactivity was found in components I and II.

appeared heterogenous, but it was poorly defined (Rehfeld, 1972). The employment of Sephadex G-50 superfine columns of the double length afforded a resolution of component III in three peaks. The first two of these peaks were eluted as the heptadecapeptides gastrins II and I respectively, and after incubation with trypsin all immunoreactivity in components I and II was found in the two heptadecapeptide-like peaks.

The small component IV was probably also present in normal subjects and patients with pernicious anaemia, but could not be clearly separated from component III due to the less sensitive fractionation procedure employed previously.

Gregory and Tracy (1972) recently isolated two pairs of gastrin from Zollinger-Ellison tumour tissue. The gastrins were identified biologically. The 'big' pair corresponded to the immunologically defined 'big' gastrin of Yalow and Berson (1970) and component II presented here. The 'small' pair corresponded to heptadecapeptide gastrins I and II in accordance with the two peaks of component III described in the present study. In addition to this pair of little gastrins Gregory and Tracy (1972) noted a third small peak of gastrin. Purification and amino-acid analysis have revealed that this peak is a tridecapeptide lacking the four $\mathrm{N}$-terminal residues of the heptadecapeptide gastrins (Gregory, personal communication). It is possible that this 'minigastrin' corresponds to the small peak eluted immediately before the salt peak (component IV) as suggested by Gregory (personal communication). The present study hence indicates that at least four gastrin components of different molecular size are circulating in Zollinger-Ellison patients. Whether these components are all paired as the heptadecapeptides, 
$\mathrm{pmol} / \mathrm{l}$

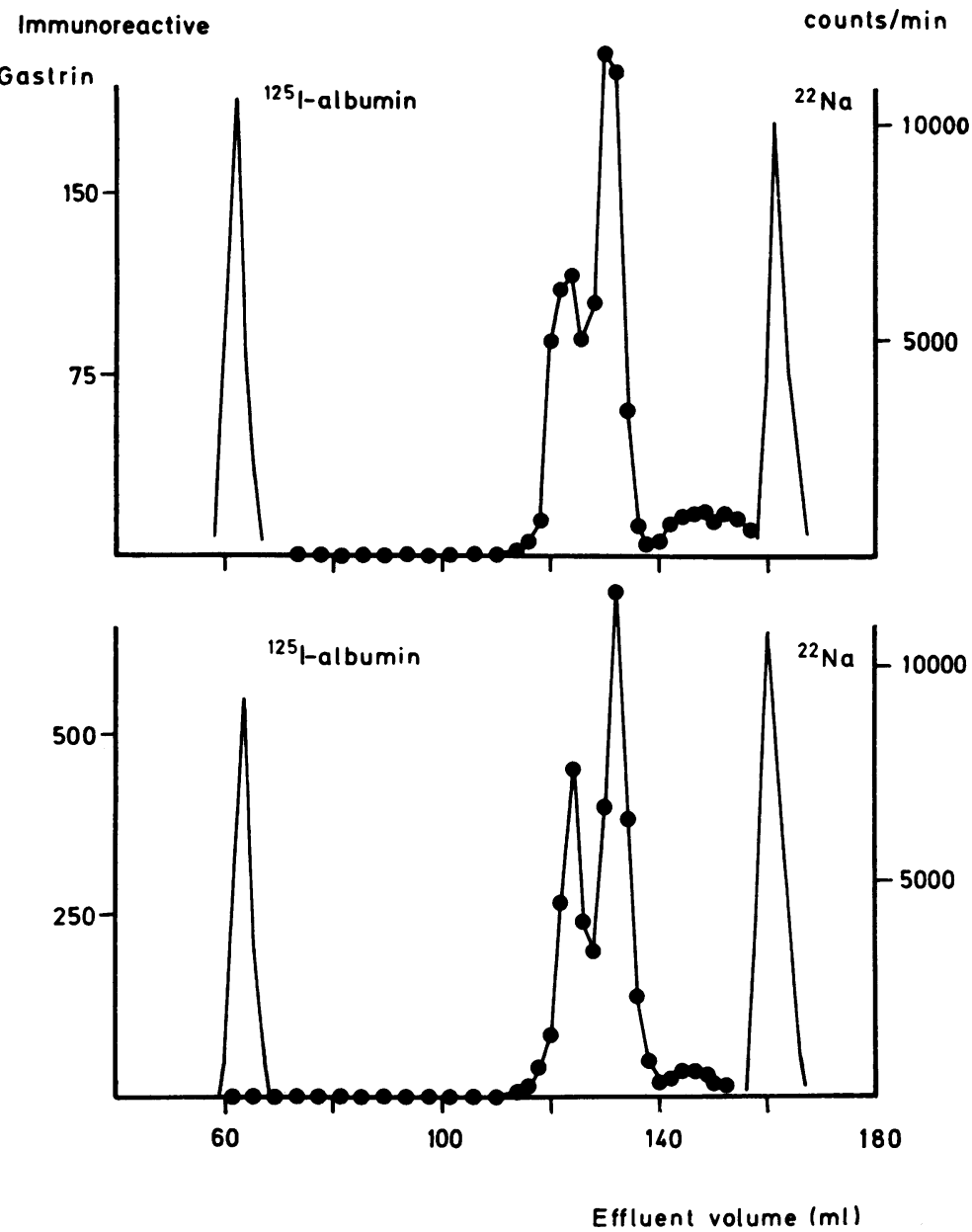

Fig 4 Elution diagram of two Zollinger-Ellison sera incubated for 30 minutes with trypsin. The normal elution diagrams for these sera are illustrated in figure 2.

gastrins I and II, and component II, remains to be solved.

In spite of a careful search for the 'big-big' gastrin reported by Yalow and Berson (1972), we could not find this gastrin component in serum from the 15 cases of Zollinger-Ellison's syndrome studied.

The skilful technical assistance of Ninna Haack, Lotte Kastoft, and Ulla Soegaard is gratefully acknowledged. We thank Dr E. Scrumpf, Aker Sykehus, Oslo, Norway, for permission to investigate sera from two Zollinger-Ellison patients. This study was supported by grants from 'Statens Lægevidenskabelige Forskningsråd', j. nr. 512-1048, 512-1665, and 512-1666, 'Det Lægevidenskabelige Forskningsfond for Storkøbenhavn, Færøerne og Grønland', and 'Landsforeningen til Kræftens Bekæmpelse'.
References

Gregory, R. A., and Tracy, H. J. (1964). The constitution and properties of two gastrins extracted from hog antral mucosa. Gut, 5, 103-117.

Gregory, R. A., and Tracy, H. J. (1972). Isolation of two 'big gastrins' from Zollinger-Ellison tumour tissue. Lancet, 2, 797-799.

Ørskov, H. (1967). Wick-chromatography for the immunoassay of insulin. Scand. J. clin. Lab. Invest., 20, 297-304.

Rehfeld, J. F. (1972). Three components of gastrin in human serum. Gel filtration studies on the molecular size of immunoreactive serum gastrin. Biochim. biophys. Acta (Amst.), 285, 364-372.

Rehfeld, J. F., Stadil, F., and Rubin, B. (1972). Production and evaluation of antibodies for the radioimmunoassay of gastrin. Scand. J. clin. Lab. Invest., 30, 221-232.

Yalow, R. S., and Berson, S. A. (1970). Size and charge distinctions between endogenous human plasma gastrin in peripheral blood and heptadecapeptide gastrins. Gastroenterology, 58, 609-615.

Yalow, R. S., and Berson, S. A. (1971). Further studies on the nature of immunoreactive gastrin in human plasma. Gastroenterology, 60, 203-214.

Yalow, R. S., and Berson, S. A. (1972). And now, 'big, big' gastrin. Biochem. biophys. Res. Commun., 48, 391-394. 